Canadian Journal of Fisheries and Aquatic Sciences

June 2008 ; Volume 65 (6) : Pages 1193-1205

http://dx.doi.org/10.1139/F08-050

(C) 2008 National Research Council Canada
Archimer http://www.ifremer.fr/docelec/ Archive Institutionnelle de l'Ifremer

The original publication is available at http://pubs.nrc-cnrc.gc.ca

\title{
A geostatistical method for assessing biomass of tuna aggregations around moored fish aggregating devices with star acoustic surveys
}

\author{
Mathieu Doray ${ }^{1,{ }^{*}}$, Pierre Petitgas $^{2}$, and Erwan Josse ${ }^{1}$ \\ ${ }^{1}$ IRD/Ifremer, US acoustique halieutique, centre IRD de Bretagne, BP 70, 29280 Plouzané \\ 2 Ifremer, Ecologie et Modèles pour l'Halieutique (EMH), rue de l'Ile d'Yeu BP 21105, 44311 Nantes Cedex 03 \\ France \\ *: Corresponding author : M. Doray, email address : $\underline{\text { mathieu.doray@gmail.com }}$
}

\begin{abstract}
:
Universal kriging was used to model the spatio-temporal variability in the acoustic density of tuna aggregations recorded during star echosounding surveys around moored fish aggregating devices (FADs) in Martinique (Lesser Antilles). The large-scale deterministic drift in the tuna spatial distribution was modeled using an advection-diffusion equation applied to animal grouping. Residuals from the drift were modeled as a random component with small-scale spatial correlation. An estimation variance formula was derived from this deterministic-statistical mixed model to assess the mean precision of density estimates of daytime tuna aggregation. The mean relative error obtained with our star design for daytime surveys was $24 \%$. The methodology was applied to estimate daily maxima of tuna biomass around moored FADs during four monthly sea cruises. The daily peak of tuna biomass aggregated around moored FADs was $9 \mathrm{t}$ on average (standard deviation $=4$ ). Estimation variances for different survey designs were compared for optimizing sampling strategy.
\end{abstract}

\section{Résumé:}

La distribution spatiale d'agrégations de thons autour de dispositifs de concentration de poissons (DCP) ancrés a été étudiée en Martinique (Petites Antilles) au moyen de parcours acoustiques en étoile. Les densités acoustiques géoréférencées attribuées aux thons ont été analysées à l'aide d'un modèle de krigeage universel. Une tendance à large échelle a été identifiée dans la distribution spatiale des thons. Cette tendance a été modélisée de façon déterministe au moyen d'une équation d'advection-diffusion appliquée aux groupes d'animaux. Les résidus de la tendance ont été modélisés comme une composante aléatoire du modèle, spatialement corrélée à faible échelle. De ce modèle, qui contenant une composante déterministe et une composante statistique, a été déduite une formule permettant de calculer la variance d'estimation de la densité diurne moyenne de l'agrégation de thons autour des DCP. L'erreur relative moyenne commise sur l'estimation de la densité de thons lors d'un parcours en étoile diurne a été estimée à $24 \%$. Cette méthode a été appliquée afin d'estimer les maxima journaliers de biomasse de l'agrégation de thons observés lors de quatre campagnes en mer mensuelles successives autour des DCP ancrés. La biomasse maximale de thons agrégée autour des DCP ancrés durant une phase diurne était en moyenne de $9 \mathrm{t}$ (écart type : 4). Les variances d'estimation obtenues avec différents parcours acoustiques ont été comparées afin d'optimiser la stratégie d'échantillonnage.

Keywords: geostatistics, tuna, moored fish aggregating devices, advection-diffusion model, acoustic survey precision 


\section{Introduction}

45 Fisheries operating around moored or drifting Fish Aggregating Devices (FADs) have been developing 46 since the 1980's (Fonteneau et al. 2000; Fréon and Dagorn 2000). Currently, they provide about half of

47 worldwide tuna catches (Fonteneau et al. 2000), taking advantage of the peculiar aggregative behavior 48 of large pelagic fish around floating objects. In spite of the economical importance of fish aggregations 49 around FADs, quantitative knowledge about these shoals is scarce. Direct survey methods, such as 50 echosounding star surveys, were developed to map fish density (Josse et al. 2000) and to characterize

51 fish aggregations around moored FADs (Doray et al. 2006, 2007). Nonetheless, the abundance of fish 52 aggregated around a FAD at a given time has never been precisely estimated. We have designed a 53 geostatistical methodology to estimate the mean density of tuna around moored FADs along with the 54 precision of that estimation (see Chiles and Delfiner (1999) for a comprehensive textbook on 55 geostatistics).

56 Computing precise density estimates based on acoustic data collected during star surveys around a 57 FAD involves i) taking into account the movements of the floating object ii) correcting the 58 oversampling of the center of the sampled area (Doonan et al. 2003), and iii) coping with the high 59 temporal variability of tuna abundance around the moored FAD (Doray et al. 2006). To account for 60 movement of the FAD, we referenced geographical positions of samples to known (recorded) FAD 61 positions. We used a universal kriging model similar to that of Petitgas (1997) to model the time62 invariant spatial structure of aggregations and to correct for oversampling the center of the survey area 63 in the kriging process.

64 In this paper we analyze the spatial distribution of daytime sub-surface tuna aggregations as observed 
65 during several star acoustic surveys conducted around moored FADs in Martinique (Lesser Antilles).

66 The mean daytime spatial distribution of tuna was estimated by averaging their acoustic density in time

67 using all surveys. This consistent component in the tuna spatial distribution (later referred to as drift or

68 trend) was modeled in a deterministic advection-diffusion framework. Then the residuals from the drift

69 were modeled as a random component with spatial correlation. The average spatial distribution of tuna

70 aggregations was thus modeled as the sum of a deterministic component for the drift and a statistical

71 one for the residuals. An estimation variance equation was derived from this mixed model for

72 estimating the mean precision of daytime acoustic star surveys. Abundance estimates and estimation

73 variances were also computed for individual surveys. Estimation variances of density obtained with our

74 star survey and other survey designs were compared in order to optimize sampling strategy.

\section{Material and methods}

\section{Data}

77 From January, 2003, to April, 2004, repeated acoustic observations were undertaken around the island 78 of Martinique on monthly sea cruises on board the $12 \mathrm{~m}$ chartered vessel "Béryx" which was equipped 79 with a Simrad EK60 scientific echosounder (version 1.4.6.72) connected to two hull-mounted, 80 spherical split-beam transducers (ES38-B and ES120-7G), operating vertically at 38 and $120 \mathrm{kHz}$ 81 frequencies. Each transducer had $7^{\circ}$ beam angles at $-3 \mathrm{~dB}$, with pulse lengths set to 0.512 ms for both. 82 In situ on-axis calibration of the echosounder was performed before each cruise using standard 83 methodology (Foote 1982). Acoustic data were archived in the international hydro-acoustic data format 84 (HAC) at a $-80 \mathrm{~dB}$ threshold with Movies+ software (Weill et al., 1993). A total of 516 star acoustic 
85 surveys (Josse et al. 2000) (Fig. 1a) were conducted within a radius of $400 \mathrm{~m}$ around 2 FADs moored 86 at 2000 and $2500 \mathrm{~m}$ depths, on the leeward coast of Martinique at 7 ('coastal FAD') and 25 ('offshore 87 FAD') nautical miles from the coast, respectively (Doray et al. 2006). During daylight hours, star 88 surveys were conducted around each FAD approximately every 2 hours, yielding an average of 11 star 89 surveys per cruise around each FAD. A unique 'sub-surface' tuna aggregation was observed in the 90 vicinity of both FADs from 35 to $87 \mathrm{~m}$ depths during almost all daytime surveys . The daytime spatial 91 distribution of the aggregation was assumed to display enough stability to allow for the estimation of 92 the tuna biomass around the FADs in each single acoustic star survey. In-situ Target Strength (TS) of 93 sub-surface tuna was analysed from the acoustic data to estimate the mean acoustic response of a single 94 tuna (Doray et al. 2006). In addition, fishing experiments were conducted to assess the mean weight of 95 sub-surface tunas around the FADs (Doray et al. 2007).

96 The echograms were processed with an image analysis algorithm implemented in Movies+ (Weill et al. 97 1993) to extract the tuna acoustic shoals from the dense surrounding scattering layers (see Doray et al. 982006 for details). This algorithm was applied to data collected at the $120 \mathrm{kHz}$ operating frequency in 50 99 daytime surveys, conducted from April to August, 2003. The acoustic records along the survey track 100 were binned in Elementary Sampling Units (ESU) of about $15 \mathrm{~m}$ in length. Acoustic densities (area 101 backscattering coefficient: $s_{a}$ (Simmonds and MacLennan 2005)) of tuna shoals detected from 0 to 200 $102 \mathrm{~m}$ depth were averaged within each ESU and allocated to the geographical position of the ESU center.

103 A schematic outline of the methodology designed to estimate the mean density of tuna aggregation and 104 the precision of star acoustic surveys is presented in Fig. 2. The position of an ESU sampled at time $t$ 105 was first referenced to the position of the head of the FAD at that time. which moved over hundreds of 
106 meters during a star survey depending on the current. Referencing the ESU positions to the FAD 107 position hence allowed restoring the geometry of star acoustic surveys conducted in strong currents. 108 During the surveys, FAD positions were recorded each time the vessel passed near the device. The time 109 varying FAD positions were estimated by modelling the trajectory of the FAD during a survey as a 110 function of time, based on recorded FAD positions. An example map with samples referenced to the 111 FAD position is illustrated in Fig. 3

112 Once referenced to the FAD head, the ESU positions were further standardised, following the 113 procedure of Okubo and Chiang (1974). The ESU coordinates in each survey were referenced to the 114 gravity center of non-zero values and their standard deviation was adjusted to equal the average 115 standard deviation of the tuna aggregation coordinates computed over all surveys. This procedure 116 resulted in scaling the dimensions of the fish aggregation around the FADs in each individual survey to 117 that of the mean aggregation estimates over all surveys. Such scaling was deemed realistic because the 118 tuna aggregation appeared to be relatively isotropic and stable from one survey to another. However, 119 fluctuations of the total tuna abundance, aggregative behavior at the tens of meter scale, and 120 environmental parameters (e.g. currents) induced some variation in the anisotropy and spreading of the 121 aggregation. Thus, we needed to filter out these variations (residuals) to characterize the mean spatial 122 distribution (drift) of the aggregation.

123 GPS positioning error (about $7 \mathrm{~m}$ in our case) was significant at the scale of our study. For each survey, 124 the surveyed area was gridded into $15 \mathrm{~m} \mathrm{x} 15 \mathrm{~m}$ cells and the average of the samples in each cell was 125 calculated and attributed to the position at the center of the cell. This procedure allowed for smoothing 126 out of GPS positioning errors by insuring that the center of each cell was located inside the $7 \mathrm{~m}$ circle 
127 of uncertainty surrounding its GPS position. Averaging tuna acoustic densities within each cell also 128 reduced the spatial variability induced by fish movements at the tens of meter scale during the surveys.

\section{The space-time model}

130 The spatial distribution of tuna around a FAD can be viewed as an outcome of their aggregative

131 behavior in the vicinity of the device, i.e. an emergent property (Allen and Starr 1982; Deneubourg and 132 Goss 1989; Parrish et al. 2002) resulting from density dependent processes operating at the scale of

133 individual tunas (Parrish and Edelstein-Keshet 1999). Within this framework, spatial distributions of 134 tuna observed during repeated surveys should be relatively similar, provided that i) the same density 135 dependent processes apply, and ii) environmental conditions are comparable. Our observations indicate 136 that the overall shape of the density surface of the tuna aggregation around each FAD stayed relatively 137 stable from one survey to another. We therefore modeled the density surface using a universal kriging 138 approach (Matheron 1971; Petitgas 2001), which allows one to distinguish between a time invariant 139 drift and spatially correlated residuals. Our model was adapted from a space-time model used to 140 estimate sole (Solea solea, L.) egg mean density in a nursery ground (Petitgas 1997).

141 The model was defined within a circular area $V$ of radius $160 \mathrm{~m}$ in standardised coordinates, centered 142 around the gravity center of the aggregation and over which $95 \%$ of the mean acoustic energy of the 143 tuna aggregation was recorded.

144 Let us denote the tuna acoustic density in cell $k$ and time $t$ as the realization $Z(k, t)$ of a random function $145 Z(x) . Z_{V}(t)$ denotes the average tuna density at time $t$ on the area $V$. The relative density at $k$ and $t$ is the 146 contribution of cell $k$ to $Z_{V}(t)$ and is denoted $Z_{p}(k, t)$. The space time model then reads 
147 (1) $Z_{p}(k, t)=\frac{Z(k, t)}{Z_{V}(t)}=m(k)+R(k, t)$,

148 where $m(k)=E\left[Z_{p}(k, t)\right]$ is the time invariant drift and $R(k, t)$ are spatio-temporal residuals with zero 149 mean.

150 We have derived the model estimating $Z_{p}(k, t)$,

$$
Z_{p}^{*}(k, t)=\frac{Z(k, t)}{Z_{a}^{*}(t)},
$$

152 where $Z_{a}^{*}(t)=\frac{1}{N_{s}(t)} \sum_{i} Z\left(k_{i}, t\right)$ is the arithmetic mean of the $N_{s}(t)$ acoustic densities sampled during

153 survey $t$. Our intention was not to precisely estimate $Z_{V}(t)$ with $Z_{a}^{*}(t) . Z_{a}^{*}(t)$ was solely used to scale 154 acoustic densities observed during surveys with different global abundances.

155 The mean spatial correlation structure in the residuals was modelled by a variogram which was 156 subsequently used to compute the estimation variance of the mean abundance estimate of i) any 157 daytime survey, ii) abundance maxima, and iii) other survey designs (Fig. 2). The model was structured 158 so that estimates from each of the surveys were interpreted as repeated estimates of the same 159 phenomenon over time. In model terms, this meant that averaging over time amounted to taking the 160 expected value of the random function $Z_{p}(k, t)$. The estimation for a given survey grid was then 161 performed using data from that grid only and inference of the spatio-temporal structure in the residuals 162 was not necessary. Hence, we solely modeled the average in time of the spatial structure in the 163 residuals. The model considered is thus a spatial model whose inference implies the use of several 
164 realizations of an underlying phenomenon.

\section{Estimation of the drift using advection-diffusion modeling of aggregations}

166 Matheron (1971) demonstrated that given one survey, drift and process residuals cannot be estimated 167 together using the same data. We therefore took advantage of the repeated surveys to estimate $m(k)$.

168 We first computed the two-dimensional (2D) arithmetic mean density surface of tuna $m_{a}^{*}(k)$ :

$169(3)$

$$
m_{a}^{*}(k)=\frac{1}{N_{s}} \sum_{t} Z_{p}^{*}(k, t),
$$

170 where $N_{s}$ is the number of times cells $k$ was sampled across all surveys. This surface was centered

171 around the gravity center of the aggregation and was remarkably isotropic, with a dome shape and

172 truncated tails near the aggregation boudaries (Fig. 4). In this regard, the mean tuna spatial distribution

173 interestingly resembled those of midge swarms modeled by Okubo and Chiang (1974) and Okubo et al.

174 (2001) using advection-diffusion equations. We therefore used these equations to model $m_{a}^{*}(k)$.

175 Okubo et al. (2001)'s model formulates that an aggregation of animals results from animal movements

176 due to different causes and occurring in opposite directions. The model assumes that, within an animal

177 group, the net one-dimensional (1D) flux $J$ of individuals through a vertical section of the group results 178 from a flux due to diffusion and an opposite flux due to advection (Okubo et al. 2001):

179 (4) $J=u S-D \frac{\partial S}{\partial x}$, 
180 where $S$ is the animal density at point $x$, while $D$ and $u$ are the diffusion and advection coefficients, 181 respectively.

182 When diffusion equals advection, $J=0$, a stable group is maintained, and (4) yields:

$183(5)$

$$
\frac{S}{\partial S} \partial x=\frac{D}{u}
$$

184 Following Okubo and Chiang (1974), a smoothing procedure (kernel smoothing) was used to formulate 185 the drift in an isotropic and continuous manner, as a function of the distance $r$ to the gravity center of 186 the aggregation. That procedure facilitated the subsequent fit of the kernel-estimated surface with the 187 advection-diffusion model.

188 Let $l$ denote the tolerance used to define distance classes. In this case, the width of distance classes is 189 defined as $r+l-(r-l)=2 l$. The kernel estimate of the relative tuna density $m_{k}^{*}(r)$ in the distance class $r$ 190 was computed as:

$$
m_{k}^{*}(r)=\sum_{r-l \leq d(x)<r+l} \frac{k_{h}(d(k)-r)}{\sum k_{h}(d(k)-r)} \times m_{a}^{*}(k)
$$

192 where $d(k)$ is the distance from the center of cell $k$ to the aggregation gravity center and $k_{h}$ is the 193 Epaneçnikov kernel of bandwidth $h$ (Stoyan and Stoyan 1994).

194 Applying Okubo et al. (2001)'s model with our tuna model notations, (5) writes: 
195 (7) $\quad \frac{m_{k}^{*}(r)}{\partial m_{k}^{*}(r)} \partial r=\frac{D}{|u|}$

196 Let $A D R$ denote the advection-diffusion ratio $D /|u|$. Similarly to Okubo and Chiang (1974), ADR

197 varied with fish density $m_{k}^{*}(r)$. That relationship was modeled explicitly, resulting in an advection-

198 diffusion model-based estimate $m_{\bmod }$ of the drift, expressed as a function of $r$.

\section{Spatial correlation in the residuals}

200 Spatial correlation modeling

201 Residuals for a survey $t$ were calculated relative to the advection-diffusion model:

$202(8)$

$$
R^{*}(k, t)=Z_{p}^{*}(k, t)-m_{\text {mod }}(k)
$$

203 The advection-diffusion model was applied for each grid cell $k$.

204 We modeled the mean correlation structure across all surveys with a variogram $\gamma$. The experimental

205 variogram in each survey $\gamma^{*}{ }_{t}(h)$ was estimated on the residuals $R^{*}(k, t)$. Then, these variograms were 206 averaged and the result was modeled by the sum of a nugget effect and a spherical model. The 207 experimental variogram of the residuals for survey $t$ was estimated using a weighting of the samples 208 (Rivoirard et al. 2000): 
$209(9)$

$$
\gamma_{t}^{*}(h)=0.5 \frac{\sum_{x_{i}-x_{j} \sim h} a\left(k_{i}, t\right) a\left(k_{j}, t\right)\left[R^{*}\left(k_{i}, t\right)-R^{*}\left(k_{j}, t\right)\right]^{2}}{\sum_{x_{i}-x_{j} \sim h} a\left(k_{i}, t\right) a\left(k_{j}, t\right)},
$$

210 where $a(k, t)$ is the area of influence of each sampled cell $k$. Areas of influence were calculated by 211 finely discretizing the study area $V$ and applying the following formula within circular areas of radius $21250 \mathrm{~m}$ centered around sampled cells centers:

$213(10) \quad a(k, t)=\frac{n_{\alpha}}{N_{c}}$

214 where $N_{c}$ is the total number of small cells in the circular area and $n_{\alpha}$ is the number of small cells 215 nearest to the sampled cell center. Weighting by area of influence was introduced to deal with the 216 sampling heterogeneity of the star survey pattern when estimating the variogram.

217 The average in time of the residual variogram was estimated using

$218(11) \quad \gamma^{*}(h)=\frac{1}{N_{s}} \sum_{t} \gamma_{t}^{*}(h)$,

219 where $N_{s}$ is the number of surveys considered.

220 Control of the average model fit and for particular surveys

221 The modeled residual variance should be comparable to those of the empirical residuals, $R^{*}(k, t)$. This 222 was checked on average over all surveys (i.e., realizations) as well as for particular surveys. The 223 average variance in the residuals was estimated empirically as well as with the model and the values 
224 compared. The empirical estimate, $s_{R}^{2}(V)$, was the average over all surveys of the survey specific 225 experimental residual variances $s_{R}^{2}(t)$. The model based estimate was

226 (12) $\quad \bar{\gamma}_{V V}=\frac{1}{V^{2}} \int_{V} d x \int_{V} \gamma(|x-y|) d y$,

227 where $\gamma$ is the mean variogram model of residuals and $x$ and $y$ are coordinates of cells within the 228 estimation domain $V$.

229 For a particular survey $t$, if the drift model $m_{\text {mod }}(k)$ was not adequate, the empirical residual variance 230 for that survey $s_{R}^{2}(t)$ would be inflated. The ability of the residual average variogram model $\gamma$ to 231 estimate the empirical residual variance of single surveys was used as a quality control parameter of the 232 adequacy of the spatial model fit to particular surveys. The adequacy for each survey $t$ of the drift 233 model $m_{\text {mod }}(k)$ and of the residual model $\gamma$ was assessed by the difference $D_{R}(t)$ between the empirical 234 residual variance $s_{R}^{2}(t)$ and the model-based variance $\bar{\gamma}_{V V}$. A low $D_{R}$ for a survey $t$ indicated a good fit 235 of the model to the data for that survey. Studying the distribution of $D_{R}(t)$ allowed for the assessment 236 of the adequacy of the spatial model to all surveys.

\section{Aggregation density and estimation variance}

\section{Mean precision of star surveys}

239 For any survey $t$, the areal mean of the tuna density $Z_{V}^{*}(t)$ was estimated by kriging (Matheron 1971). 
240 The kriging estimate of the areal mean is

$241(13)$

$$
Z_{V}^{*}(t)=\sum_{i} \lambda_{i} Z\left(k_{i}, t\right)
$$

242 where $\lambda_{i}$ are kriging weights summing to unity. Kriging weights are defined so as to minimize the 243 estimation variance (Rivoirard et al. 2000). The estimation variance is not conditional on the data 244 values of a given survey and writes (Petitgas, 1997):

$$
\sigma_{E}^{2}=E\left[Z_{V}^{2}(t)\right] \times \operatorname{Var}\left(Z_{p, V}(t)-Z_{p, V}^{*}(t)\right)=E\left[Z_{V}^{2}(t)\right] \times \sigma_{s p a}^{2}
$$

246 where $Z_{p, V}^{*}(t)$ is the estimation of the areal mean of the relative density in survey $t$ and $\sigma_{s p a}^{2}$ the 247 estimation variance of $Z_{p, V}^{*}(t)$.

248 Within the framework of the universal kriging model, $\sigma_{s p a}^{2}$ develops in two error variance terms, $\sigma_{m}^{2}$ 249 and $\sigma_{R}^{2}$, which are associated with the drift and the residuals respectively (Matheron 1971)

$250(15) \quad \sigma_{s p a}^{2}=\sigma_{m}^{2}+\sigma_{R}^{2}=\frac{\sigma_{E}^{2}}{E\left[Z_{V}^{2}(t)\right]}$

$251 \sigma_{m}^{2}$ was estimated by $1-R^{2}, R^{2}$ being the coefficient of determination of the fit of $m_{k}^{*}(k)$ with $m_{\text {mod }}(k)$ 252 (Scherrer 1984) 
$253(16)$

$$
R^{2}=\frac{\sum\left(m_{\mathrm{mod}}-\bar{m}_{k}^{*}\right)^{2}}{\sum\left(m_{k}^{*}-\bar{m}_{k}^{*}\right)^{2}}
$$

254 The error term associated with the residuals was estimated by a geostatistical estimation variance 255 (Rivoirard et al. 2000)

$$
\sigma_{R}^{2}=2 \sum_{i} \lambda_{i} \bar{\gamma}\left(x_{i}, V\right)-\bar{\gamma}(V, V)-\sum_{i} \sum_{j} \lambda_{i} \lambda_{j} \gamma\left(k_{i}, k_{j}\right),
$$

257 where $\gamma$ is the model of the mean variogram of residuals, $\lambda_{i}$ kriging weights summing to unity and $k$ the 258 cells sampled by the most regular star survey conducted during the cruises.

$259 E\left[Z_{V}^{2}(t)\right]$ was estimated by $E\left[Z_{a}^{* 2}(t)\right]$, the time average of squared daytime arithmetical mean 260 acoustic densities $Z_{a}^{*}(t)$ and the standard (estimation) error $S E$ by

$261(18)$

$$
S E=\frac{\sigma_{E}}{E\left[Z_{a}^{*}(t)\right]}
$$

\section{Abundance estimates}

263 The spatial mean of the tuna aggregation acoustic density, $Z_{V}(t)$, was estimated for each survey $t$ by

264 kriging the survey mean relative density surface, $Z_{p}(k, t)$, then scaling the kriged relative estimate with

265 the survey data average, $Z_{a}^{*}(t)$. For kriging, we used the time-invariant model $\gamma$ of the mean residual 
266 variogram; the survey mean estimate was calculated as

267 (19)

$$
Z_{V}^{*}(t)=\sum_{i} \lambda_{i} Z\left(k_{i}, t\right)=Z_{a}^{*}(t) \sum_{i} \lambda_{i} Z_{p}\left(k_{i}, t\right)
$$

268 where $\lambda_{i}$ are the kriging weights summing to unity.

269 Because of the higher density sampling near the FAD centers introduced by the star survey geometry, 270 we used kriging to optimally weight the sample values according to each survey configuration and 271 average variogram structure.

272 Finally, the abundance $A$ and biomass $B$ of tuna in the area $V$ were computed as:

$273(20) \quad A(t)=\rho_{A} \times V=\frac{Z_{V}^{*}(t)}{\left\langle\sigma_{b s}\right\rangle} \times V$ and $B(t)=A(t) \times \bar{W}$,

274 where $\rho_{A}$ is the density of tuna within the aggregation $\left(\mathrm{Nb}\right.$. fish.m $\mathrm{m}^{-2}$, while $\left\langle\sigma_{b s}\right\rangle$ and $\bar{W}$ are the mean 275 backscattering cross-section (Simmonds and MacLennan 2005) and mean weight of a single tuna, 276 respectively. The mean TS value of a sub-surface tuna given by Doray et al (2007) $(-35 \mathrm{~dB})$ was used

277 to compute $\left\langle\sigma_{b s}\right\rangle$ as: $\left\langle\sigma_{b s}\right\rangle=10^{T S / 10}$. We used $2.7 \mathrm{~kg}$ as $\bar{W}$ estimate, based on the mean fork length of 278 sub-surface tuna given by Doray et al (2007) $(58 \mathrm{~cm})$ and a length-weight relationship established for 279 blackfin tuna caught around moored FADs in Martinique (Rivolaen et al 2007).

280 This methodology was applied to assess daily maxima of tuna abundance observed during the sea 281 cruises. Daily maxima of abundance were defined by selecting the survey with the highest mean 
282 arithmetic tuna density $\left(Z_{a}^{*}(t)\right)$ in each surveyed $24-\mathrm{h}$ period.

\section{Other survey patterns}

284 Once spatial correlation in fish distribution is modeled, one can compute and compare estimation 285 variances of various survey designs (Petitgas and Lafont 1997). We compared the precision in our star 286 survey with that for other star survey designs. We assumed that all surveys would provide similar $m$,

$287 \sigma_{m}^{2}$ and $\gamma$ and focused on the differences in $\sigma_{R}^{2}$ due to differences in survey design.

288 The sample positions needed to compute estimation variances were obtained by applying various 289 survey designs on a virtual tuna aggregation. We positioned a circular aggregation in a $400 \mathrm{~m} \mathrm{x} 400 \mathrm{~m}$ 290 area divided into $15 \times 15 \mathrm{~m}$ cells centered around a virtual FAD. Aggregation dimensions and the 291 relative position from the FAD were identical to those of observed average sub-surface tuna 292 aggregation (Doray et al. 2006). Survey designs described in Table 1 were applied to the virtual 293 aggregation. Branches of star designs were sampled along two parallel tracks ('with duplicate' as in Fig. 294 1a) or along a single track ('without duplicate' as in Fig. 1b). Sample positions obtained with each 295 design were used to compute residual estimation variances $\sigma_{R}^{2}$ in a circular estimation area of radius $296160 \mathrm{~m}$, centered around the gravity center of the aggregation. Estimation variances were computed 297 using equation 17 and the variogram model $\gamma$.

298 Statistics were implemented using the R language (R Development Core Team 2007). Geostatistical 299 computations were implemented using EVA2 software (Petitgas and Lafont 1997) and R packages 300 geoR (Ribeiro and Diggle 2001) and RgeoS (Renard and Bez 2005). 


\section{Results}

\section{Drift characterisation}

303 As stated earlier, the arithmetic mean estimate of the drift $m_{a}^{*}(x)$ presented in Fig. 4 shows an isotropic 304 distribution relative to the distance from the gravity center, justifying a 1D modeling approach

305 To estimate the drift $m_{k}^{*}(r)$, a kernel of bandwidth $35 \mathrm{~m}$ was selected to compute tuna density 306 estimates in distance classes of $5 \mathrm{~m}$ width (Fig. 5). Values of bandwidth and distance class width were 307 adjusted to select the best-fitting model (highest R-squared) of the kernel-estimated drift with the 308 advection-diffusion model. The advection-diffusion ratio $A D R(=D /|u|)$ varied with the distance from 309 the aggregation gravity center (Fig. 5). The ratio decreased in a central region within $120 \mathrm{~m}$ from the 310 aggregation center and showed some low amplitude oscillations beyond $120 \mathrm{~m}$. The $A D R$ decreased 311 sharply within $30 \mathrm{~m}$ from the center and more steadily between 30 to $120 \mathrm{~m}$. Within the model 312 framework, the diffusive component (random individual tuna trajectories) would therefore be higher 313 close to the aggregation center and would rapidly decrease toward the edges. Fluctuations in gradients 314 usually materialize boundaries of system elements (Allen and Starr 1982). ADR oscillations observed 315 beyond $120 \mathrm{~m}$ from the aggregation center could materialize the aggregation boundary i.e. the limits of 316 the area of applicability of the advection-diffusion model.

317 The $A D R$ displayed a strong relationship with the drift of the tuna density (Fig. 6). The relationship was 318 modeled on a log scale using two linear models $l m_{1}$ and $l m_{2}$, fitted over two distinct parts of the curve 319 (Fig. 6). The analytical model characterising the relationship between $A D R$ and $m_{k}^{*}(r)$ was 
320

(21) $\left\{\begin{array}{lll}\log (D /|u|)=\alpha_{1} \log \left(m_{k}^{*}\right)+\beta_{1} \Leftrightarrow D /|u|=\left(m_{k}^{*}\right)^{\alpha_{1}} e^{\beta_{1}} & \text { for } & m_{k}^{*} \in\left[m_{k, L}^{*} ; m_{k, \max }^{*}\right] \\ \log (D /|u|)=\alpha_{2} \log \left(m_{k}^{*}\right)+\beta_{2} \Leftrightarrow D /|u|=\left(m_{k}^{*}\right)^{\alpha_{2}} e^{\beta_{2}} & \text { for } & m_{k}^{*} \in\left[m_{k, \min }^{*} ; m_{k, L}^{*}[,\right.\end{array}\right.$

322 where $m_{k, \text { min }}^{*}$ and $m_{k, \text { max }}^{*}$ are the minimum and maximum $m_{k}^{*}$ values, and $m_{k, L}^{*}$ is the value of $m_{k}^{*}$ at the 323 intersect between $\operatorname{lm}_{1}$ and $l m_{2}$.

324 By replacing $A D R$ in Equation 7 by its expression in Equation 21 and after integration, we obtain an 325 analytical model $m_{\text {mod }}$ for the drift

326
(22)
$\left\{\begin{array}{l}m_{\bmod }=\left(\left(m_{k, \max }^{*}\right)^{\alpha_{1}}-\alpha_{1} \times r \times e^{-\beta_{1}}\right)^{1 / \alpha_{1}} \\ m_{\bmod }=\left(\left(m_{k, L}^{*}\right)^{\alpha_{2}}-\alpha_{2}\left(r-m_{k, L}^{*}\right) \times e^{-\beta_{2}}\right)^{1 / \alpha_{2}}\end{array}\right.$
for $r \in\left[r_{\min } ; r_{L}[\right.$
for $r \in\left[r_{L} ; r_{\max }\right]$,

328 where $r_{\min }$ and $r_{\max }$ are the minimum and maximum distances from the gravity center of the aggregation,

329 while $r_{L}$ is the distance for which $m_{k}^{*}=m_{k, L}^{*}$.

330 The intercept between $l m_{1}$ and $l m_{2}$ was defined to minimize the residual sum of squares of the fit of

$331 m_{k}^{*}(r)$ with $m_{\bmod }(r)$. The best fit provided a $R^{2}$ value of 0.99 and was obtained at $r_{L}=45 \mathrm{~m}$ (Fig. 7).

332 No relation was found between the variance of residuals $R^{*}(x, t)$ computed in time and the drift value 333 at point $x$. The universal kriging model was therefore additive. We computed means weighted by area 334 of influences for each map of residuals. The average value of map means was close to zero $(0.12, \mathrm{SD}=$ 335 0.12), meaning that the advection-diffusion model estimate of the drift was unbiased. 


\section{Spatial correlation modeling}

337 Fig. 8 shows the residuals variogram with its fit. The model was fit using the goodness of fit criterion 338 proposed by Rivoirard et al. (2000). The fit model $\gamma$ is spherical with a nugget of 2 , a range of $52 \mathrm{~m}$ and 339 the sill at 1.8. The spherical component of the variogram accounts for $50 \%$ of the total modeled 340 variance (i.e. the sums of sills). This indicates that the residuals are significantly spatially correlated, 341 justifying the universal kriging approach.

342 The average empirical residual variance $s_{R}^{2}(V)$ (3.87) compared well with its model-based estimate

$343 \bar{\gamma}_{V V}$ (3.73), meaning that the model residual variance is on average well scaled over all realizations.

344 Considering variance in particular surveys, the distribution of $D_{R}$ was skewed towards large positive

345 values (Fig. 9), corresponding to surveys with relatively high $s_{R}^{2}(t)$ values. However, its mean was

346 close to zero $(0.15, \mathrm{SD}=2.5)$ and represented only $4 \%$ of the mean $s_{R}^{2}(t)$ value. The residual variance

347 unexplained by the spatial correlation model $\gamma$ was therefore generally low. The spatial model was 348 hence considered appropriate to represent the survey data.

\section{Precision of daytime star surveys}

350 The estimation variance term associated with the mean residuals computed using the variogram model

351 in Equation 17, was $\sigma_{R}^{2}$. The global estimation variance for any of the daytime star surveys was

$$
352 \sigma_{E}^{2}=E\left[Z_{V}^{2}(t)\right] \times \sigma_{s p a}^{2}=E\left[Z_{V}^{2}(t)\right] \times\left(\sigma_{m}^{2}+\sigma_{R}^{2}\right)=3.58 \times 10^{-10} \times(0.01+0.02)=1.07 \times 10^{-11},
$$


353 with a standard error of

$354 S E=\frac{\sigma_{E}}{Z_{V T}^{*}}=\frac{\sqrt{1.07 \times 10^{-11}}}{1.39 \times 10^{-5}}=24 \%$.

\section{Estimates of daily maximum abundance}

356 Table 2 presents 11 estimates of tuna daily maximum abundance around the two moored FADs 357 surveyed from April, 2003, to August, 2003. Daily maxima of abundance were generally observed 358 around noon (mean time: 12:27, $\mathrm{SD}=03: 09$ ) (Table 2). The mean estimate of tuna daily maximum 359 abundance was 9 MT, with no significant differences noted between the two surveyed FADs.

360 In order to obtain information on the way kriging weights operated on the different surveys, we 361 computed the average of the weights in classes of distance from the head of the FAD. Kriging weights 362 decreased towards the center of the domain $V$ in all of these surveys. The mean weights taken over all 363 surveys (Fig. 10) illustrate that trend. Kriging weights therefore correct the oversampling of the center 364 of the area.

\section{Sampling effort and star survey precision}

366 Fig. 11 shows the residual estimation variance $\sigma_{R}^{2}$ obtained with different star survey designs as a 367 function of sampling effort. Designs star2d and star4, as well as designs star4d and star8 have similar 368 effort but different number of branches. Designs with higher number of branches yielded the lowest 369 estimation variance as they sample space more evenly.

370 A total of three star designs with duplicate (star4d, star6d and star8d) and two designs without 
371 duplicate (star6 and star8) yielded low estimation variances. The star8 survey design (Fig. 1b) provided

372 a relatively low estimation variance with a moderate sampling effort. It could provide a good trade-off

373 between precision and sampling effort but could be more difficult to complete than the star8d design in 374 strong current conditions.

\section{Discussion}

376 To our knowledge, this study is the first attempt to define a methodology for analyzing acoustic data 377 obtained during star surveys to estimate the abundance of tuna aggregations around moored FADs.

378 Based on repeated surveys, we observed that the tuna aggregations around the two FADs showed a 379 predictable distribution pattern in which fish abundance decreased with the distance from the head of 380 the FAD. The distribution pattern was modeled with a generic advection-diffusion model of animal 381 grouping. We made use of the universal kriging method which allowed dealing with the deterministic 382 spatial component as well as residual spatial variations. The precision of the survey estimate then 383 depended not on all the spatial variability but only on that of the residuals, theoretically giving a lower 384 estimation variance. We considered repeated surveys as different realizations of the aggregation 385 phenomenon around the FADs and used the repetitions to infer an average non-stationary spatial 386 model. Our (average) model can be used to map the aggregation around the FAD and estimate its 387 abundance and estimation variance. We used the model for an average survey set up and compared 388 different survey designs. We also used the model for particular surveys and performed the estimation 389 for these using the average model and the particular sample locations for these surveys.

390 Assuming that these two surveyed FADs are representative of others, the procedure for analyzing

391 repeated star surveys around moored FADs can be summarized as follows (Fig. 2): (a) record the 
392 position of the head of the FAD during the survey, (b) center the sample positions relative to the FAD's 393 head, (c) normalize the sample positions using the standard deviation of positions, (d) grid the survey 394 area and estimate the average fish density in each cell, (e) normalize each cell value by the survey 395 average and estimate relative densities, (f) perform (a) to (e) for each survey of a series of repeated 396 surveys and estimate the average relative density surface across surveys, (g) model the deterministic 397 component in the relative density surface: model the decrease in average relative density from the 398 center of the aggregation to its borders using a 1D advection-diffusion model, (h) estimate 2D residuals 399 in each cell for each survey, (i) estimate a variogram for the residuals, and (j) estimate the survey mean 400 and its precision by kriging. In the previous procedure we used different weightings at different steps. 401 In step (e) we used the simple data average to normalize each cell value, mainly for simplicity's sake. 402 In step (i) we used spatial weights (area of influence) to estimate the residual variogram as suggested in 403 Rivoirard et al. (2000). In step (j) we used kriging weights to estimate the survey mean around the FAD 404 and its precision.

405 Using simulations, Doonan et al. (2003) tested different survey plans and analysis methods for star 406 surveys. They used a bi-gaussian function to parameterize the decrease in abundance from the center to 407 the border of the aggregation. The advection-diffusion model used here is biologically more 408 informative and also more generic than a bi-gaussian surface. The advection-diffusion model can adapt 409 to a variety of gaussian-like spatial patterns in the data where the shape in the decrease of the 410 abundance from the center to the border is parameterized by the relationship between the $A D R$ 411 (advection diffusion ratio) and the abundance. Doonan et al. (2003) also suggested transforming star 412 survey sample cartesian coordinates to polar coordinates, resulting in transforming the star design into 
413 a series of parallel transects. Though seemingly practical, this procedure will result in producing a 414 discontinuity in the transformed design at the middle of the star design, exactly where the fish 415 aggregation is more continuous. This is thought to result in increasing the estimation variance. Kriging 416 (by weighing the samples optimally) will counterbalance the oversampling effect of the star survey at 417 the middle of the star and we see no need to transform the coordinates to resolve that particular effect.

418 In our analysis, the most important aspect to deal with was the correct estimation and interpretation of 419 the deterministic component in the aggregation around the head of the FAD. The drift component was 420 successfully modeled within an advection-diffusion framework using 50 star surveys conducted over a 421 four month period. How many surveys are indeed required to infer the drift? To answer this question, 422 we applied the mean precision estimation methodology to subsets of 40,30, 20, 10 and 5 surveys 423 randomly selected between the initial 50 surveys to estimate the amount of surveys required to get a 424 realistic drift model, as well as a reasonable level of precision, The drift was successfully modeled with 425 ten surveys and more, using kernel bandwidths ranging from 35 to $40 \mathrm{~m}$. The mean surface density 426 computed with five surveys showed too much anisotropy to allow for the fitting of the advection427 diffusion model, whatever the bandwidth used in the kernel estimation procedure. Variogram models of 428 residuals and precision levels were similar while using 20 surveys and more. The spherical component 429 of the variogram model computed with 10 surveys accounted for only $33 \%$ of the sums of sills. This 430 absence of strong spatial structure in the residuals makes the use of the universal kriging model 431 questionable in this instance. The proportion of total variance assigned to spatial autocorrelation in the 432 variogram model can hence provide guidance to decide whether to use the universal kriging model. 433 These results suggest that our methodology requires a minimum of 20 surveys to provide a reasonable 
434 estimate of the drift and good precision levels. However, over larger time and spatial scales, 435 characteristics of the spatial aggregation can be expected to vary (e.g., seasonal and or regional 436 variations in the drift as well as in the residual spatial correlation). We therefore suggest using the 437 distribution of $D_{R}(t)$ as a quality control criterion to judge for the adequacy of the average spatial 438 model for each of the repeat cruises. In the larger ensemble of cruises around the two FADs in 439 Martinique, data from 5 surveys were not well fitted with the model presented in this study. They 440 showed exceptionally dense and localized abundance patches and were characterized by high residual 441 variance with no spatial correlation in the residuals. Their geostatistical spatial aggregation index 442 (Petitgas 1998) was significantly higher than that of other surveys (see test in Petitgas 1998). As the 443 fish density surface of these surveys dramatically departed from the drift, they were excluded from the 444 present analysis and would require a separate analysis.

445 The high regularity of the mean tuna density surface indicates that the density surfaces of tuna 446 aggregations observed during each survey were roughly similar. This suggests that the spatial 447 distribution of tuna observed at the macroscopic scale of the area $V$ during each survey may result from 448 identical, time invariant processes occurring at the microscopic scale of individual tunas. The fact that 449 the drift component in the spatial distribution was successfully modeled within an advection-diffusion 450 framework suggests that these microscopic time invariant processes could be analogous to advection451 diffusion. Within the framework of the model, the dome-shaped, tails truncated spatial distribution of 452 midge and tuna aggregations is explained by the dominance of diffusion near the center of the 453 aggregation and by the increase of advective processes that generate sharp edges at the aggregation 454 boundaries. Okubo and Chiang (1974) validated their model by directly estimating realistic advection 
455 and diffusion coefficients based on individual midge velocities. In the same way, studying the small456 scale 3D individual trajectories of tuna aggregated around a FAD with acoustic tags should allow 457 validation of the use of the Okubo et al. (2001) advection-diffusion model in the case of tuna 458 aggregations. Moreover, Okubo et al.'s (2001) model is valid for stable groups with no gain and loss of 459 animals. Most studies on residence time of tuna around moored FADs (Musyl et al. 2003; Girard et al. 460 2004; Ohta and Kakuma 2005) suggest that this hypothesis may hold at the temporal scale of a star 461 survey (30 minutes). However, tuna aggregations around moored FADs are thought to be at least partly 462 maintained at a larger temporal scale by a dynamical equilibrium between emigrating and immigrating 463 fishes (Girard et al. 2004; Doray et al. 2006). Therefore, more realistic models of tuna aggregation 464 processes around FADs should include the large scale gain and loss of individuals.

465 When large numbers of FADs equipped with radio beacons are deployed, searching time no longer 466 provides a measure of fishing effort, as FADs concentrate fish in known areas. As a consequence, it is 467 now very difficult to use the catch per unit effort as an index of local abundance in stock assessment 468 models (Ariz Telleria et al. 1999; Fréon and Misund 1999; Fonteneau et al. 2000). Stock assessment 469 models that take into account the aggregative behavior of large pelagic fish have been developed (Clark 470 and Mangel 1979; Samples and Sproul 1985; Hilborn and Medley 1989), but their implementation is 471 hindered by the lack of field estimations of exchange rates between aggregated and non-aggregated 472 populations (Fréon and Misund 1999). Our methodology could serve to compute precise abundance 473 estimates around drifting FADs. This would be a first step toward quantitative field assessment of gain 474 and loss of fishes associated with drifting FADs. These flux estimates could be used as proxys of 475 exchange rates between aggregated and non-aggregated populations in stock assessment models. In the 
476 same way, if one assumes that the tuna abundance in the close vicinity of a FAD is proportional to the 477 mesoscale abundance of aggregated tuna in open waters surrounding the device, precise local 478 abundance estimates obtained around FADs could be used to get insights into the distribution and 479 abundance of aggregated tuna in global pelagic ecosystems.

480 Ackowledgments: This research was co-funded by the European Community, the Regional Council 481 and the prefecture of Martinique. The authors gratefully thank the crew of the "Béryx" for their 482 invaluable assistance during the sea cruises, as well as Eric Mittlestaed and Gene Vricella for 483 correcting the English text. The referees and the editor are thanked for thoughtful comments that 484 greatly improved the manuscript. 


\section{References}

486 Allen T., and Starr T. 1982. Hierarchy perpectives for ecological complexity. Univ. Of Chicago, 487 Chicago, USA.

488 Ariz Telleria J., Delgado de Molina A., Fonteneau A., Gonzales Costas F., and Pallarès P. 1999. Logs 489 and tunas in the eastern tropical Atlantic: A review of present knowledge and uncertainties. In 490 Proceedings of the International Workshop on the Ecology and Fisheries for Tunas Associated with 491 Floating Objects, February 11-13, 1992, La Jolla, USA: p. 21-65.

492 Clark C., and Mangel M. 1979. Aggregation and fishery dynamic: a theoretical study of schooling and 493 the purse seine tuna fishery. Fish. Bull. 77: pp. 317-337.

494 Chiles J., and Delfiner P. 1999. Geostatistics: Modeling Spatial Uncertainty. Wiley, New York (USA). 495 Deneubourg J., and Goss S. 1989. Collective patterns and decision making. Ethology Ecology \& 496 Evolution 1: pp. 295-311.

497 Doonan I., Bull B., and Coombs R. 2003. Star acoustic surveys of localized fish aggregations. ICES J. 498 Mar. Sci. 60: pp. 132-146.

499 Doray M, Josse E, Gervain P, Reynal L and Chantrel J, 2007. Joint use of echosounding, fishing and 500 video techniques to assess the structure of fish aggregations around moored Fish Aggregating 501 Devices in Martinique (Lesser Antilles). Aquat. Liv. Res. 20.

502 Doray M., Josse E., Gervain P., Reynal L., and Chantrel J. 2006. Acoustic characterisation of pelagic 503 fish aggregations around moored fish aggregating devices in Martinique (Lesser Antilles). Fish. Res. 504 82: pp. 162-175.

505 Fonteneau A., Pallarés P., and Pianet R. 2000. A worldwide review of purse seine fisheries on FADs. 
506 In Proceedings of the Tuna Fishing and Fish Aggregating Devices Symposium, Trois Ilets, 507 Martinique pp. 15-35.

508 Foote K.G., 1982, Optimizing copper spheres for precision calibration of hydroacoustic equipment. J. 509 Acoust. Soc. Am. 71, 742-747.

510 Fréon P., and Misund O. 1999. Dynamics of Pelagic Fish Distribution and Behaviour: Effects on

511 Fisheries and Stock Assessment. Blackwell Science, London, UK.

512 Fréon P., and Dagorn L. 2000. Review of fish associative behaviour: toward a generalisation of the 513 meeting point hypothesis. Rev. Fish Biol. Fish. 10: pp. 183-207.

514 Girard C., Benhamou S., and Dagorn L. 2004. FAD: Fish Aggregating Device or Fish Attracting

515 Device? A new analysis of yellowfin tuna movements around floating objects. Anim. Behav. 67: pp. $516 \quad 319-326$.

517 Hilborn R., and Medley P. 1989. Tuna purse-seine with fish aggregating devices (FAD): models of 518 tuna FAD interactions. Can. J. Fish. Aquat. Sci. 44: pp. 1366-1369.

519 Josse E., Dagorn L., and Bertrand A. 2000. Typology and behaviour of tuna aggregations around fish 520 aggregating devices from acoustic surveys in French Polynesia. Aquat. Living Resour. 13: pp. $521 \quad 183-192$.

522 Matheron G. 1971. The theory of regionalised variables and its applications. Les Cahiers du Centre de 523 Morphologie Mathématiques, Fascicule 5. Centre de Géostatistique, Ecole Nationale Supérieure des 524 Mines de Paris, Fontainebleau, France.

525 Musyl M.K., Brill R.W., Boggs C.H., Curran D.S., Kazama T.K., and Seki M. P. 2003. Vertical 526 movements of bigeye tuna (Thunnus obesus) associated with islands, buoys, and seamounts near the 527 main Hawaiian Islands from archival tagging data. Fish. Oceanogr. 12: pp. 152-169. 
528 Ohta I., and Kakuma S. 2005. Periodic behavior and residence time of yellowfin and bigeye tuna 529 associated with fish aggregating devices around Okinawa Islands, as identified with automated 530 listening stations. Mar. Biol. 146: pp. 581-594.

531 Okubo A., and Chiang H. 1974. An analysis of kinematics of swarming of Anarete pritichiardi Kim 532 (Diptera: Cecidomyiidae). Res. Popul. Ecol. 16: pp. 1-42.

533 Okubo A., Grünbaum D., and Edelstein-Keshet L. 2001. The Dynamics of Animal Grouping. In 534 Diffusion and ecological problems: Modern Perspectives. Second Edition. Edited by Okubo A., and 535 S.A. Levin. Springer-Verlag, Berlin, Germany pp. 197-237.

536 Parrish J.K., and Edelstein-Keshet L. 1999. Complexity, pattern, and evolutionary trade-offs in animal 537 aggregation. Science 284: pp. 99-101.

538 Parrish J.K., Viscido S.V., and Gruenbaum D. 2002. Self-Organized Fish Schools: An Examination of 539 Emergent Properties. Biol. Bull. Mar. Biol. Lab. Woods Hole 202: pp. 296-305.

540 Petitgas P., and Lafont T. 1997. EVA2: Estimation variance. Version 2, A geostatistical software on 541 Windows 95 for the precision of fish stock assessment surveys. ICES CM 1997/Y:22: .

542 Petitgas P. 1997. Sole egg distribution in space and time characterised by a geostatistical model and its 543 estimation variance. ICES J. Mar. Sci. 54: pp. 213-225.

544 Petitgas P. 1998. Biomass-dependent dynamics of fish spatial distributions characterized by 545 geostatistical aggregation curves. ICES J. Mar. Sci. 55: pp. 443-453.

546 Petitgas P. 2001. Geostatistics in fisheries survey design and stock assessment: models, variances and 547 applications. Fish. Fish. 2: pp. 231-249.

548 R Development Core Team 2007. R: A language and environment for statistical computing. R 549 Foundation for Statistical Computing, Vienna, Austria. ISBN 3-900051-07-0, URL http://www.R- 
550 project.org.

551 Renard D., and Bez N. 2005. RGeoS: Geostatistical Package. R package version 2.1. Centre de 552 Géostatistique, Ecole des Mines de Paris, Fontainebleau, France.

553 Ribeiro P., and Diggle P. 2001. geoR: a package for geostatistical analysis. R-NEWS 1: pp. 15-18.

554 Rivoalen J.J., Lagin A., Norbert M.H., and Reynal L. 2007. Relations taille-poids et fréquences de 555 taille par catégorie commerciale des principales espèces capturées autour des dispositifs de 556 concentration de poissons ancrés en Martinique. FAO Fish. Rep. 797: pp. 161-179.

557 Rivoirard J., Bez N., Fernandes P., Foote K., and Simmonds J. 2000. Geostatistics for Estimating Fish 558 Abundance. Blackwell Science, Oxford, UK.

559 Samples K., and Sproul J. 1985. Fish aggregating devices and open-access commercial fisheries. Bull. 560 Mar. Sci. 37: 305-317.

561 Scherrer B. 1984. Biostatistique. Gaëtan Morin, Boucherville, Québec.

562 Simmonds E.J., MacLennan D.N., 2005, Fisheries acoustics. theory and practice. Blackwell publishing, 563 Oxford.

564 Stoyan D., and Stoyan H. 1994. Fractals, random shapes and point fields. Wiley, New York, USA.

565 Weill A., Scalabrin C., and Diner N. 1993. MOVIES-B: An acoustic detection description software. 566 Application to shoal species' classification. Aquat. Living Resour. 6: pp. 255-267. 


\section{Tables}

568 Table 1. List of the star survey designs tested for their precision.

\begin{tabular}{ccc}
\hline Code & $\begin{array}{c}\text { Survey designs } \\
\text { (centered around virtual FAD) }\end{array}$ & $\begin{array}{c}\text { Sampling effort } \\
\text { (Nb. of sampled cells) }\end{array}$ \\
\hline Star2d & 2 branches star pattern, with duplicate & 128 \\
Star4d & 4 branches star pattern, with duplicate & 256 \\
Star6d & 6 branches star pattern, with duplicate & 384 \\
Star8d & 8 branches star pattern, with duplicate & 512 \\
Star2 & 2 branches star pattern, without duplicate & 64 \\
Star4 & 4 branches star pattern, without duplicate & 128 \\
Star6 & 6 branches star pattern, without duplicate & 192 \\
Star8 & 8 branches star pattern, without duplicate & 256 \\
\hline
\end{tabular}


569 Table 2. Estimates of tuna maximum daily abundance around moored FADs.

\begin{tabular}{|c|c|c|c|c|c|c|c|c|c|c|}
\hline FAD & Date & Time & $\begin{array}{c}\mathrm{Z}_{\mathrm{a}}^{*} \\
\left(\mathrm{~m}^{-2} \cdot \mathrm{m}^{-2}\right)\end{array}$ & $\begin{array}{c}\mathrm{Z}_{\mathrm{v}} * \\
\left(\mathrm{~m}^{-2} \cdot \mathrm{m}^{-2}\right)\end{array}$ & $\sigma_{\mathrm{E}}^{2}$ & $\sigma_{\text {spa }}^{2}$ & SE & $\begin{array}{c}\rho_{\mathrm{a}}(\mathrm{Nb} . \\
\left.\text { Fish }^{-2} \mathrm{~m}^{-2}\right)\end{array}$ & $\begin{array}{c}\text { A (Nb. } \\
\text { fish) }\end{array}$ & $\begin{array}{c}\mathrm{B} \\
(\mathrm{MT})\end{array}$ \\
\hline Coastal & 29 Apr. 2003 & $12: 30$ & $3.84 \times 10^{-05}$ & $2.41 \times 10^{-05}$ & $6.48 \times 10^{-11}$ & 0.04 & $33 \%$ & 0.08 & 6130 & 17 \\
\hline Coastal & 3 Jul. 2003 & $07: 45$ & $1.41 \times 10^{-05}$ & $1.34 \times 10^{-05}$ & $1.28 \times 10^{-11}$ & 0.06 & $27 \%$ & 0.04 & 3409 & 9 \\
\hline Coastal & 4 Jul. 2003 & $15: 30$ & $9.52 \times 10^{-06}$ & $7.58 \times 10^{-06}$ & $4.80 \times 10^{-12}$ & 0.05 & $29 \%$ & 0.02 & 1928 & 5 \\
\hline Coastal & 11 Jul. 2003 & $12: 20$ & $2.33 \times 10^{-05}$ & $1.62 \times 10^{-05}$ & $3.21 \times 10^{-11}$ & 0.06 & $35 \%$ & 0.05 & 4128 & 11 \\
\hline Coastal & 3 Aug. 2003 & $16: 30$ & $1.71 \times 10^{-05}$ & $1.61 \times 10^{-05}$ & $1.36 \times 10^{-11}$ & 0.05 & $23 \%$ & 0.05 & 4098 & 11 \\
\hline Coastal & 4 Aug. 2003 & $17: 00$ & $2.18 \times 10^{-06}$ & $1.17 \times 10^{-06}$ & $2.09 \times 10^{-13}$ & 0.04 & $39 \%$ & 0.00 & 297 & 1 \\
\hline Coastal & 5 Aug. 2003 & $12: 00$ & $1.48 \times 10^{-05}$ & $1.07 \times 10^{-05}$ & $1.01 \times 10^{-11}$ & 0.05 & $30 \%$ & 0.03 & 2722 & 7 \\
\hline Offshore & 6 Aug. 2003 & $12: 30$ & $1.57 \times 10^{-05}$ & $1.08 \times 10^{-05}$ & $1.02 \times 10^{-11}$ & 0.04 & $30 \%$ & 0.03 & 2750 & 7 \\
\hline Offshore & 7 Aug. 2003 & 07:00 & $1.58 \times 10^{-05}$ & $1.29 \times 10^{-05}$ & $1.14 \times 10^{-11}$ & 0.05 & $26 \%$ & 0.04 & 3270 & 9 \\
\hline Offshore & 8 Aug. 2003 & $11: 45$ & $1.87 \times 10^{-05}$ & $1.52 \times 10^{-05}$ & $1.59 \times 10^{-11}$ & 0.05 & $26 \%$ & 0.05 & 3859 & 10 \\
\hline Offshore & 8 Aug. 2003 & $12: 15$ & $1.68 \times 10^{-05}$ & $1.44 \times 10^{-05}$ & $1.23 \times 10^{-11}$ & 0.04 & $24 \%$ & 0.05 & 3652 & 10 \\
\hline \multicolumn{2}{|r|}{ Mean } & $12: 27$ & $1.69 \times 10^{-05}$ & $1.30 \times 10^{-05}$ & $1.71 \times 10^{-11}$ & 0.05 & $29 \%$ & 0.04 & 3295 & 9 \\
\hline
\end{tabular}




\section{Figure captions}

571 Fig. 1. Star survey designs. (a) 8 branches with duplicate (star8d) (b) 8 branches without duplicate 572 (star8).

573 Fig. 2 . Schematic outline of the methodology designed to estimate the mean density and precision of 574 star acoustic surveys of tuna aggregations associated to moored fish aggregating devices.

575 Fig. 3. Example of acoustic tuna density map obtained during a star survey around a moored fish 576 aggregating device (FAD) in Martinique. The radius of each circle is proportional to $s_{a}$ values $\left(\mathrm{m}^{2} \cdot \mathrm{m}^{-2}\right)$ 577 recorded in each elementary sampling unit.

578 Fig. 4. Spatial distribution of the arithmetic mean of relative acoustic tuna density recorded during 579 daytime surveys in the longitudinal (solid line) and latitudinal (broken line) directions.

580 Fig. 5. Kernel (empty circles) and arithmetic (filled circles) one-dimensional estimate of the mean 581 relative tuna density, with the advection-diffusion ratio overlaid (triangles).

582 Fig. 6. Advection-diffusion ratio as a function of tuna kernel density estimate (empty circles) with the 2 583 parts-linear model overlaid (broken lines).

584 Fig. 7. Fit of the advection-diffusion model (solid line) with the one-dimensional distribution of tuna 585 kernel density estimate (empty circles), $\mathrm{R}^{2}=99 \%$.

586 Fig. 8. Mean experimental variogram of residuals (dots). The fitted model (solid line) is a nugget of 587 value 2 added to a spherical model of sill 1.8 and range $52 \mathrm{~m}$.

588 Fig. 9. Boxplot of the differences $D_{R}(t)$ between the empirical residual variance $s_{R}^{2}(t)$ and the model- 
589 based variance $\bar{\gamma}_{V V}$, for each survey $t$. The horizontal bold line represents the median, the lower and 590 upper edges of the box the first and third quartile, and the lower and upper whiskers the limits of the $59195 \%$ confidence interval for the median. Empty dots are outliers lying beyond the extremes of the 592 whiskers.

593 Fig. 10. Mean krigging weights as a function of the distance from the head of the fish aggregating 594 device (FAD).

595 Fig. 11. Residual estimation variance $\sigma_{R}^{2}$ as a function of sampling effort for different star survey 596 designs described in Table 1. 
597 Figures
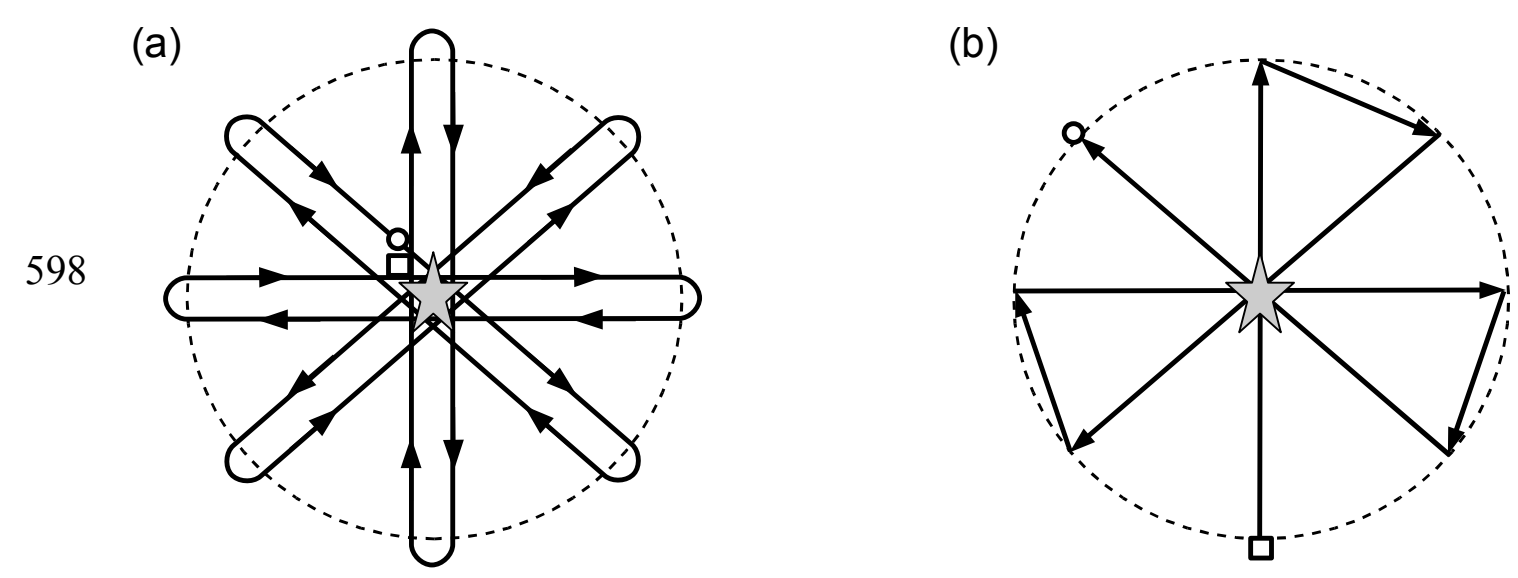

599 Fig. 1. 
Single survey

\begin{tabular}{|c|c|c|}
\hline $\begin{array}{l}\text { Center the sample positions } \\
\text { relative to the FAD's head } \\
\text { positions }\end{array}$ & \multicolumn{2}{|c|}{$\begin{array}{l}\text { Estimate the average relative } \\
\text { density surface across surveys }\end{array}$} \\
\hline 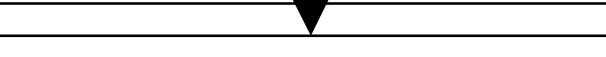 & \multicolumn{2}{|c|}{7} \\
\hline Normalize the sample positions & \multirow{2}{*}{\multicolumn{2}{|c|}{$\begin{array}{c}\text { Model the decrease in average } \\
\text { relative density from the center of } \\
\text { the aggregation to its borders } \\
\text { using a } 1 \mathrm{D} \text { advection-diffusion } \\
\text { model }\end{array}$}} \\
\hline $\begin{array}{c}\text { Grid the survey area and estimate } \\
\text { the average fish density in each } \\
\text { cell }\end{array}$ & & \\
\hline $\begin{array}{l}\text { Estimate relative densities, define } \\
\text { aggregation limits }\end{array}$ & & \\
\hline $\begin{array}{l}\text { Estimate } 2 \mathrm{D} \text { residuals in each cell } \\
\text { for each survey }\end{array}$ & \multicolumn{2}{|c|}{$\begin{array}{l}\text { Estimate a variogram model for } \\
\text { the residuals }\end{array}$} \\
\hline $\begin{array}{l}\text { Estimate the survey mean and its } \\
\text { precision by kriging }\end{array}$ & \multirow[b]{2}{*}{$\begin{array}{l}\text { Estimate the } \\
\text { mean survey } \\
\text { precision by } \\
\text { kriging }\end{array}$} & \multirow[b]{2}{*}{$\begin{array}{l}\text { Estimate } \\
\text { precision of } \\
\text { other survey } \\
\text { designs }\end{array}$} \\
\hline $\begin{array}{c}\text { Estimate the aggregation biomass } \\
\text { using mean individual TS and } \\
\text { weight }\end{array}$ & & \\
\hline
\end{tabular}

601 Fig. 2. 


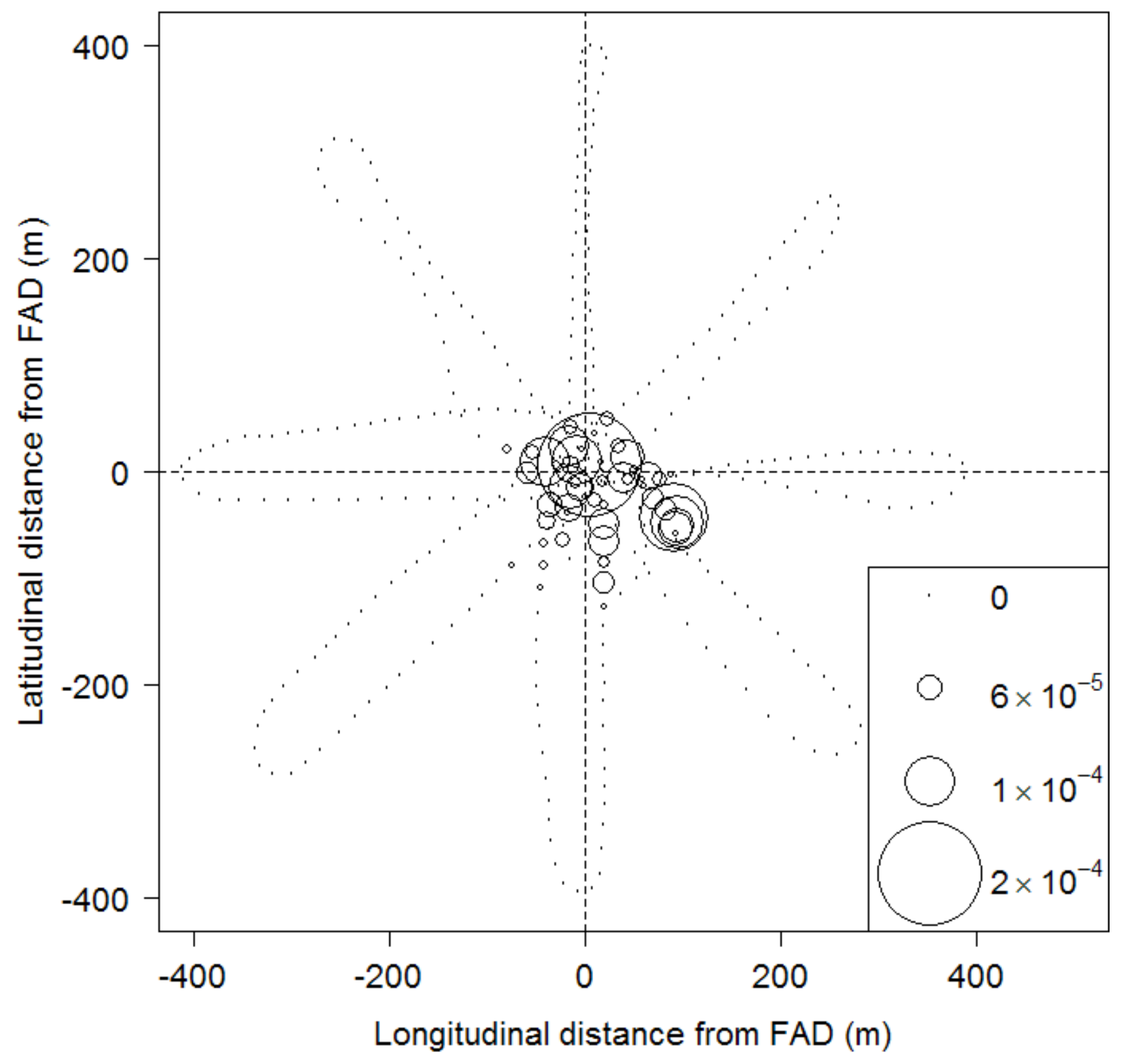

602 Fig. 3. 


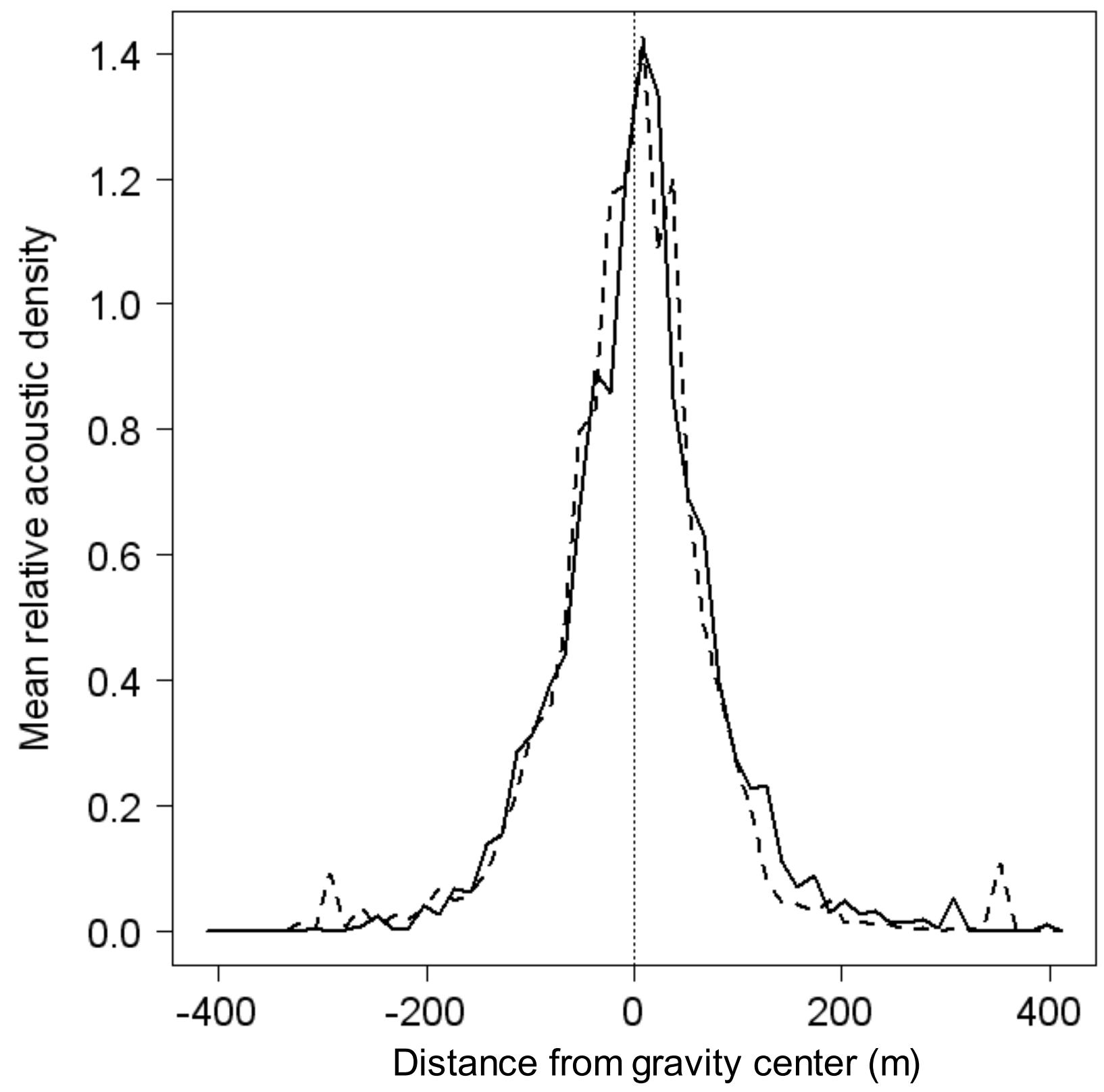

603

604 Fig. 4. 


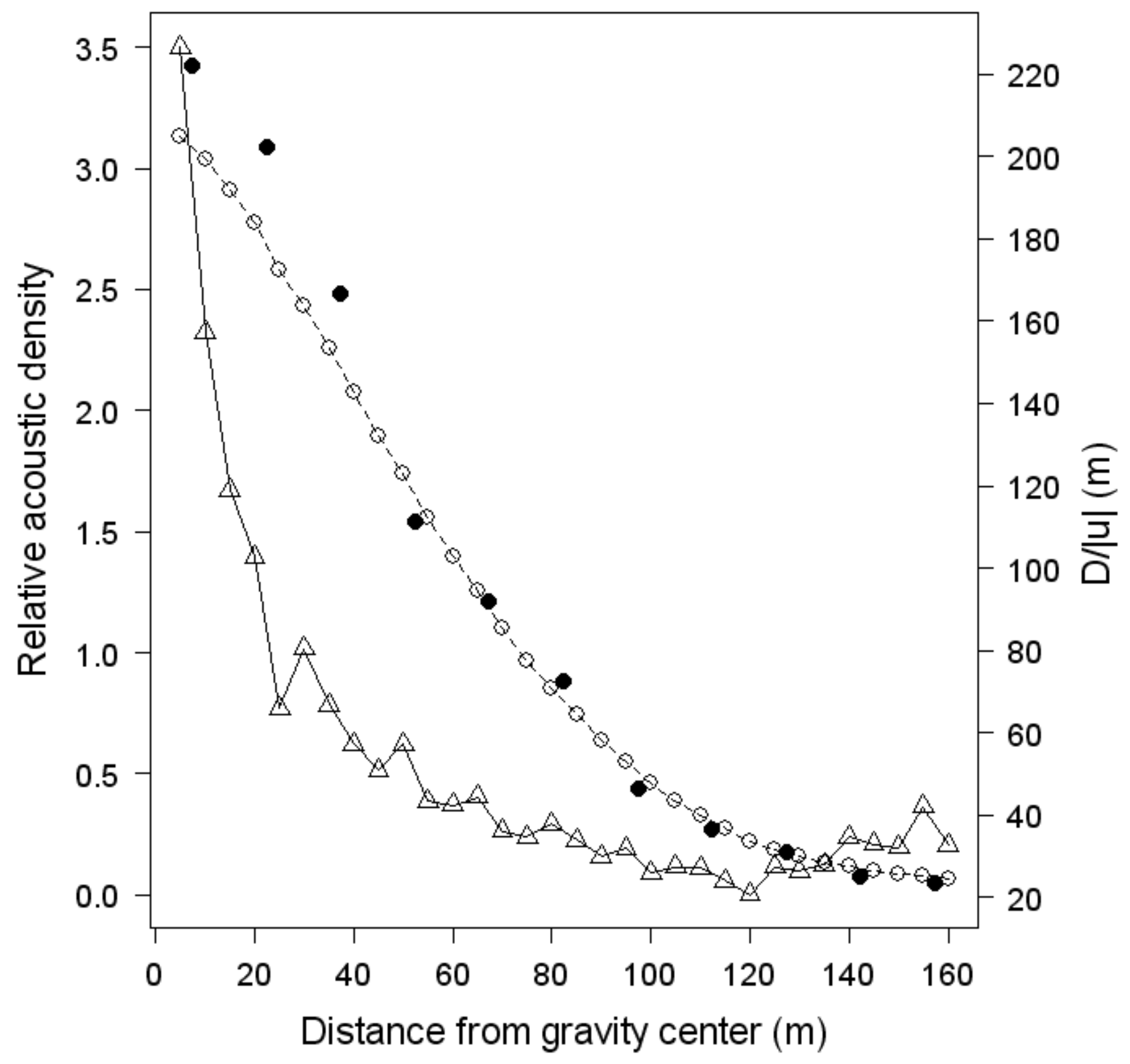

605

606 Fig. 5. 


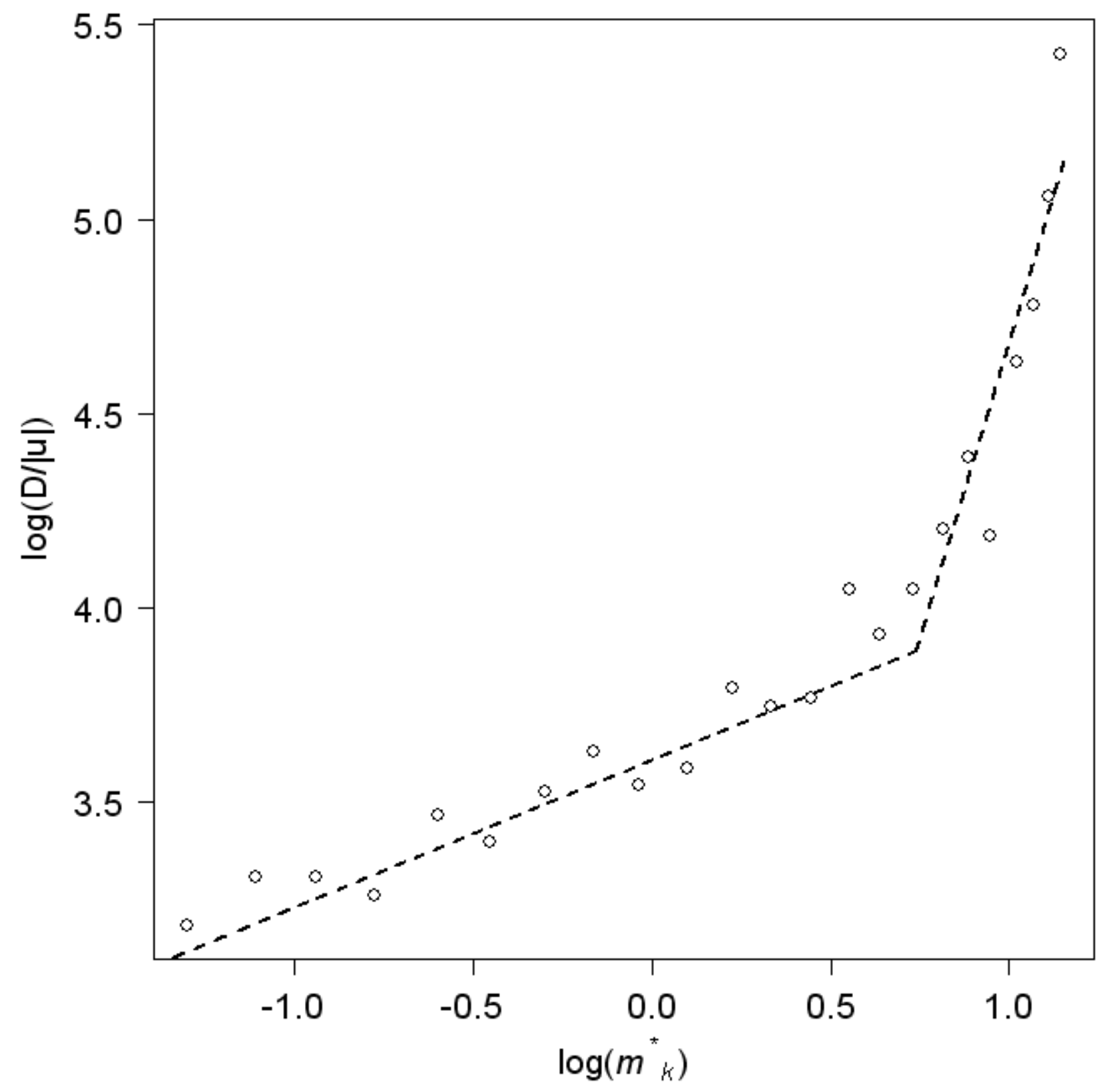

607

608 Fig. 6. 


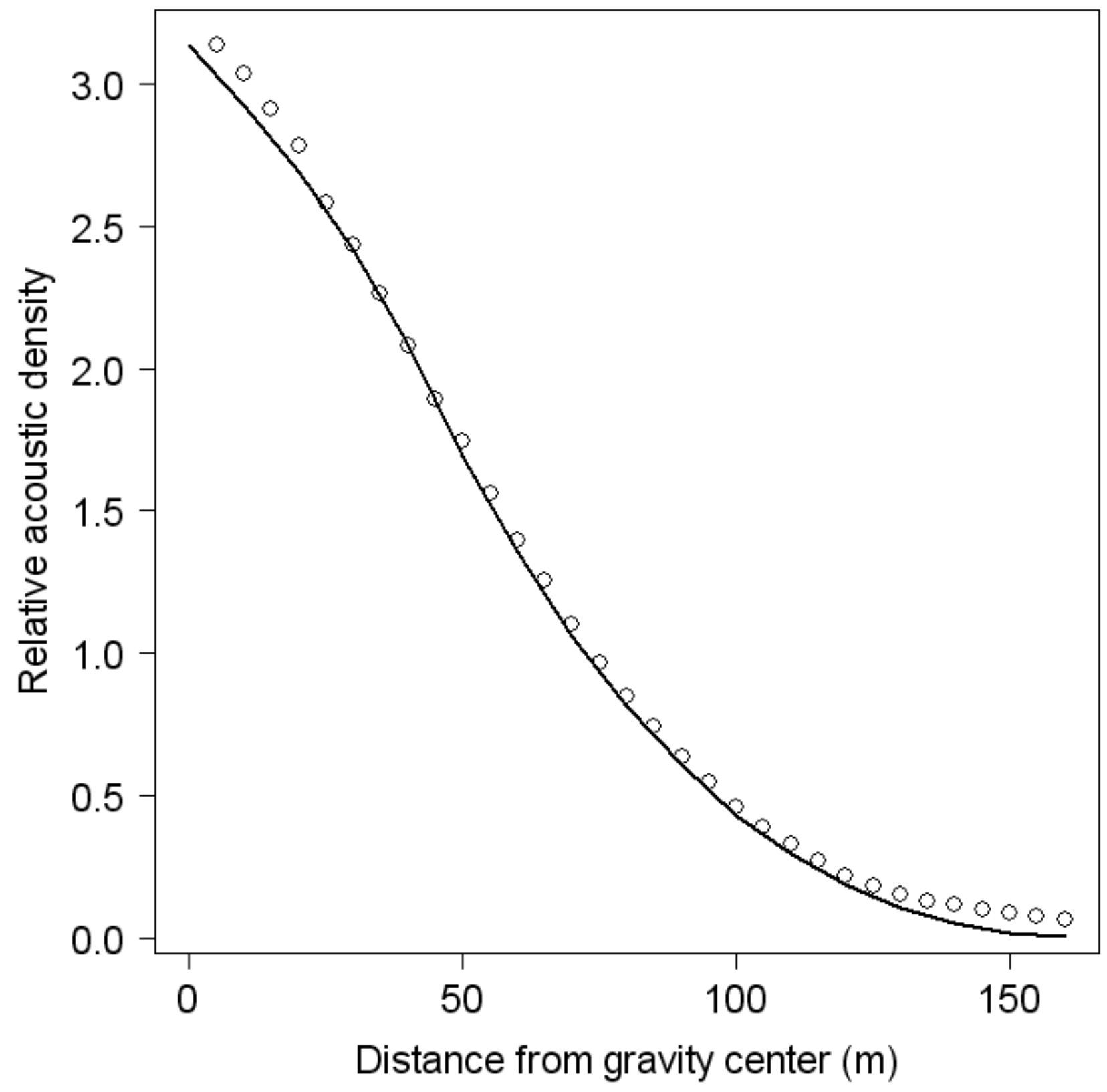

609

610 Fig. 7. 


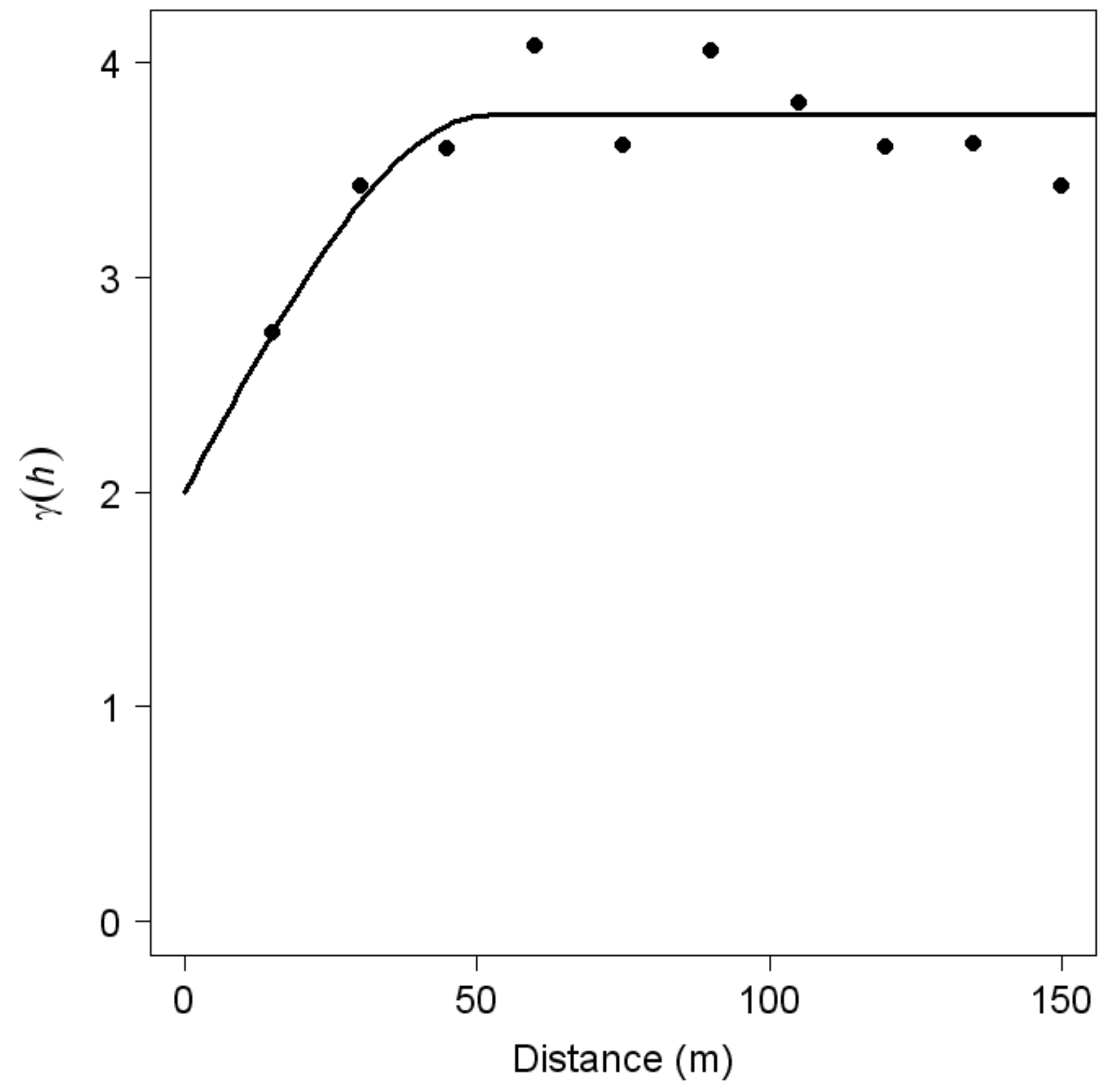

611

612 Fig. 8. 


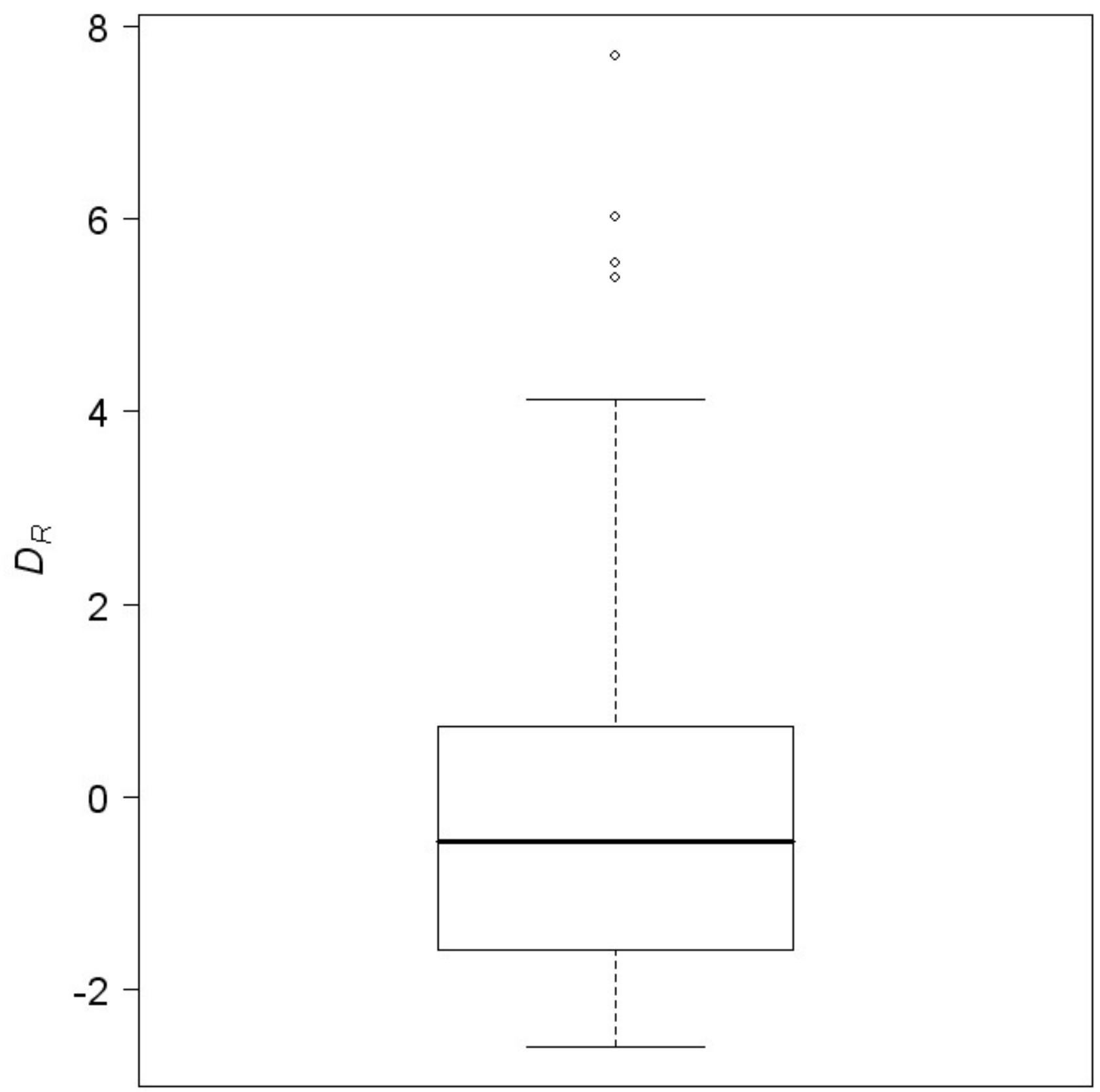

613

614 Fig. 9. 


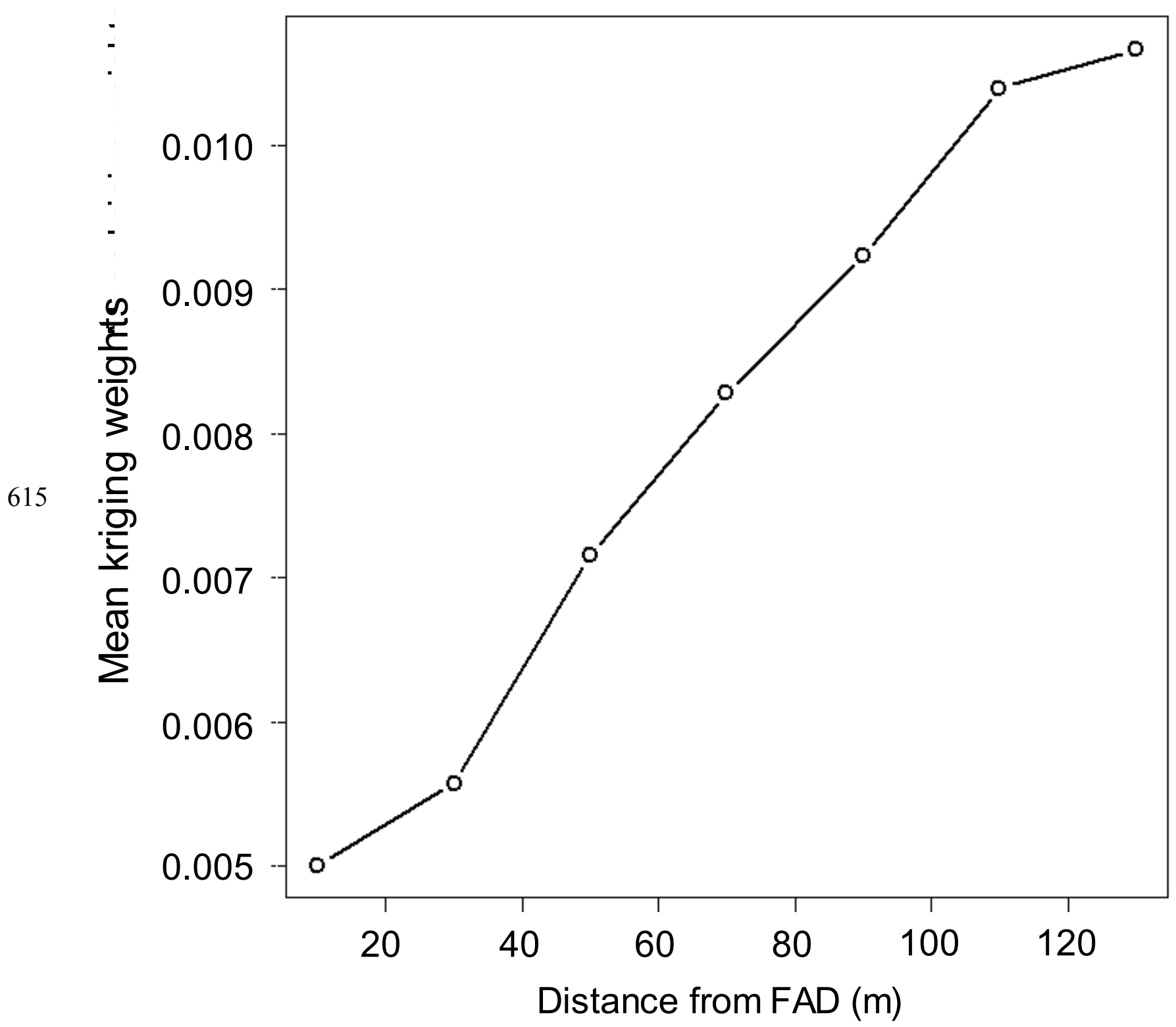

616 Fig. 10. 


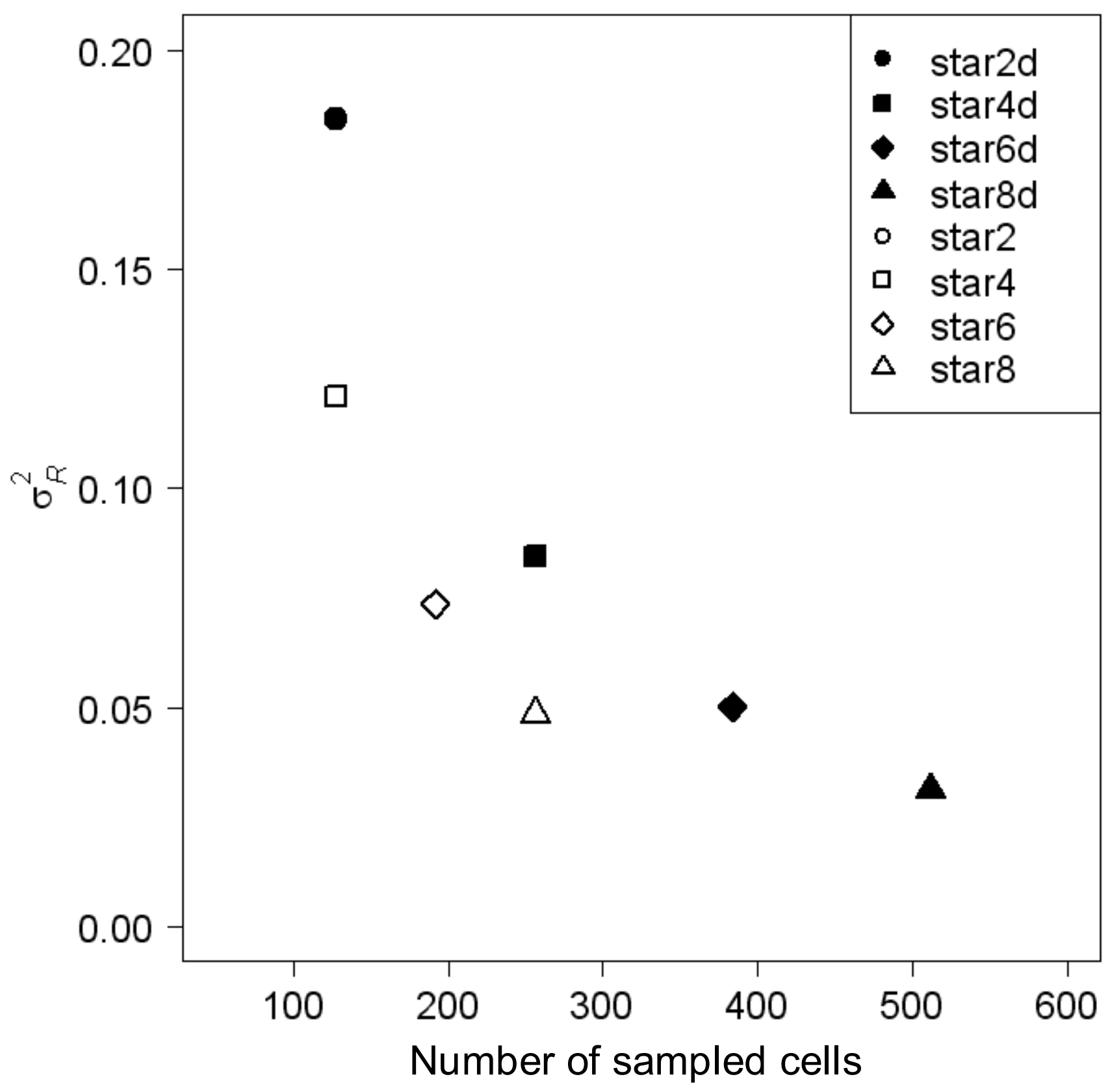

617

618 Fig. 11. 